\title{
Intraoperative damage to the urinary bladder during cesarean section - literature review
}

\author{
Andrzej Korniluk ${ }^{1}$, Przemysław Kosiński ${ }^{2}$, Mirosław Wielgoś ${ }^{2}$ \\ ${ }^{1}$ Mazovia Regional Hospital in Siedlce, Poland \\ ${ }_{2}^{2} 7^{\text {st }}$ Department of Obstetrics and Gynecology, Medical University of Warsaw, Poland
}

\section{INTRODUCTION}

The last years have brought a significant increase in the number of births by caesarean section, and as a result there is expected to be an increasing number of patients with adhesions in the pelvis minor on a more frequent basis. Intrauterine adhesions are the most significant risk factors of damage to the bladder. The incidence of damage to the bladder during the caesarean section is relatively small. However, it is extremely important to anticipate the possibility of this complication, its early intraoperative diagnosis and implementation of appropriate treatment when they occur.

Damage to the urinary tract, which is a complication of caesarean section, is rarely described in the literature. However, the caesarean section is now the most frequently performed obstetric surgery in the world, and their number increases every year. Taking this into account, the obstetricians and their patients should be aware of the potential complications associated with carrying out this procedure.

Over the last century, the reduced rates of morbidity and mortality of mothers during caesarean section are noticeable, but a growing number of urological complications are expected to be seen. The most common urological complication of caesarean section is the damage of the urinary bladder [1].

Incidence of bladder damage after cesarean section ranges from 0.08 to $0.94 \%$ [2-8]. The data on injuries of the urinary bladder during caesarean section, however, are divergent because the available manuscripts use inconsistent definitions of damage and do not specify the severity of damage.

Although bladder damage during cesarean delivery is rare, obstetricians should be aware of the need to inform pregnant women about all the possible complications as- sociated with this operation before giving informed consent for the caesarean section. The potential consequences of damage to the bladder are connected with the extension of the duration of operation, longer hospitalization time, the need to keep Foley catheter longer in the urinary bladder, the increase of infections and post-operative complications in the urinary tract, such as vesico-vaginal fistula.

The possibility of this type of complications should be also expected and it is necessary to point out that the most important is to establish the diagnosis even during the caesarean section.

In this paper, the following aspects are discussed: the risk factors, diagnosis and treatment options of damage to the bladder during caesarean section.

\section{HOW TO AVOID DAMAGE?}

The contemporary methods of cesarean section are mainly modification of the operation performed by Pfannenstiel method, which is the method described at the turn of the $19^{\text {th }}$ and $20^{\text {th }}$ centuries. This procedure is usually not a single surgical technique, and in many centers there are well-established types of this surgical technique. In order to minimize the damage of the urinary bladder, it is necessary to analyze different surgical techniques.

In analyzing how to perform caesarean section and its impact on the traumatism of the urinary bladder, it should be stated that the way to open the abdominal wall (modification of Pfannenstiel method, or longitudinal midline cut) does not change the probability of damage [8]. About $28.0-46.6 \%$ of damage to the bladder occurs during the opening of the peritoneum [7-9]. In the studies of some authors, bladder injuries, which occur during the opening of the peritoneum, dominate during the first cesarean section 
Table 1. Time of creating damage to the bladder [7-9]

\begin{tabular}{|l|c|c|}
\hline The moment of damage to the urinary bladder & First-time caesarean section & Repeated caesarean section \\
\hline Opening of the peritoneum & $35.7-46.6 \%$ & $35.7-46.6 \%$ \\
\hline Opening of vesico-uterine pouch & $23.8-50.0 \%$ & $32.0-60.0 \%$ \\
\hline The opening of the uterus and the fetus extraction & $14.3-28.6 \%$ & $35.7-46.6 \%$ \\
\hline Closure of the hysterotomy & $10 \%$ & $10 \%$ \\
\hline
\end{tabular}

Table 2. The percentage of adhesions in the abdominal cavity depending on the number of caesarean section [18-20]

\begin{tabular}{|c|c|}
\hline Number of cesarean sections & $\begin{array}{c}\text { The risk of adhesions in the } \\
\text { peritoneal cavity }\end{array}$ \\
\hline 2 & $21.6-24.0 \%$ \\
\hline 3 & $32.3-42.9 \%$ \\
\hline Next & $42.2-47.9 \%$ \\
\hline
\end{tabular}

Table 3. Location of the damage to the urinary bladder $[8,9]$

\begin{tabular}{|l|c|c|}
\hline $\begin{array}{l}\text { The place of damage } \\
\text { to the bladder }\end{array}$ & $\begin{array}{c}\text { First-time } \\
\text { caesarean section }\end{array}$ & $\begin{array}{c}\text { Repeated } \\
\text { caesarean section }\end{array}$ \\
\hline Dome & $51.0-76.2 \%$ & $48.0-53.3 \%$ \\
\hline Body & $21.8-24 \%$ & $46.7-52.0 \%$ \\
\hline Trigone & $0-3.0 \%$ & $3.0-8 \%$ \\
\hline
\end{tabular}

(46.6\%), while the subsequent cesarean section predisposes to injuries in the opening of vesico-uterine pouch (32.0$-60.0 \%)[2,7-9]$. Opening the peritoneum using the "sharp" method (Pfannenstiel method), compared to the opening with the "blunt" method (Joel-Cohen and Misgav-Ladach methods) seems to be the safer method, especially if it is the subsequent cesarean section [7]. In the Pfannenstiel and Joel-Cohen methods the vesicouterine fold of peritoneum may be incised so the bladder can be separated from the uterus to expose the lower uterine segment for incision, as described previously by Kerr [10]. Sliding the bladder down reduces the risk of injury particularly in the repeated cesarean section. Forming the bladder flap at least $1-2 \mathrm{~cm}$ above the top edge of the bladder can minimize the risk of bladder injury. Hysterotomy without forming bladder flap, as in the - Misgav-Ladach method and its modifications, seems to be safe mostly at first cesarean section. Special attention should be paid to this stage of the surgery, because about $23.8 \%$ of damage in case of women who give birth for first time and up to $60.0 \%$ of injuries in case of the next cesarean section is made at that moment $[2,7-9]$. Approximately $14.3 \%$ of injuries occur at the time of hysterotomy (in the following caesarean section, this value rises up to $40 \%$ ) [8].

In most cases, the uterus is opened laterally with a scalpel in the lower section on a length of about $2 \mathrm{~cm}$, and then it is extended bluntly or sharply with fingers. There were no differences found in the incidence of uterine rupture in the published studies or the anticipated loss of blood or ease of extraction of the fetus [11, 12]. Unfortunately, in these studies, no reference was made to the urinary bladder damage [12]. The method of transverse opening of the uterus is safer compared to the infrequently used uterine incision in the midline in the lower section (De Lee and Cornell methods).

Sometimes, there is a need to enlarge the incision of the uterus in order to extract the fetus. Although no comparative studies were found of a way to extend the incision, it appears that in order to reduce the risk of injury to the bladder, extension of the hysterotomy slit should be performed in the cephalad direction.

The integral part of the cesarean by the Pfannestiel method is bladder flap repair. The distant consequence of such a technique is the greater chance of adhesions in the lower segment of the uterus, which may lead to difficulties in the subsequent ceasarian section and damage to the bladder [7, 8, 13-15]. Therefore, what seems reasonable is avoiding suturing of the peritoneum as in the Joel-Cohen and Misgav-Ladach methods.

The available studies found no significant differences in the impact of suturing vesicovaginal peritoneum on the prevalence of bladder injury [14].

On the other hand, however, there are studies that have shown beneficial effects on pertinoneum repair in reducing formation of adhesions [16, 17].

The probability of bladder damage increases with the times of performing the caesarean section. According to many authors, subsequent cesarean section causes approximately 4-5 fold increase in the risk of damage to the bladder $[2,7,8]$.

The main risk factor of damage to the bladder is presence of peritoneal adhesions. The adhesions in the peritoneal cavity in combination with previous cesarean section increase the risk of damage to the bladder ten-fold [8]. The probability of adhesions grows with subsequent caesarean section.

The most frequently diagnosed are the adhesions of abdominal wall, bladder and uterus with the parietal peritoneum. The pathogenesis of adhesion formation is a complex process in which fibrin, clotting factors and inflammatory cells repair the peritoneum $[19,21]$.The risk factors for adhe- 
sions are as follows: individual predisposition, the presence of blood in the abdominal cavity, tissue ischemia, infection, excessive use of surgical instruments or direct manipulating abdomial organs [19]. Separation of the scarred tissues should be carried out using the sharp method. In the case of suspected massive adhesions, the peritoneal cavity should be opened higher than usual.

Among the documented risk factors of damage to the bladder are, for instance: abdominal surgeries, fibroids in the lower section of the uterus or endometriosis [7].

Most of the publications indicate that the total number of defects of the bladder is greater in elective caesarean sections than in case of emergency cesarean sections. This is due to the fact that majority of elective cesarean sections are in patients after at least one cesarean section or in older patients [7, 8]. It should be uderlined, however, that a caesarean section, due to emergency indications, can cause haste, especially in case of less experienced surgeons, which may favor the occurrence of complications [22].

The stage of delivery is also important in the occurrence of certain risks of damage to the urinary bladder. The risk of damage to the bladder increases four-fold in the second stage of labor, compared to the $1^{\text {st }}$ stage of labor [8, 23].

The reason for this risk growth is complex. Compression of the fetal presenting part changes the local blood supply to the bladder wall by increasing its vulnerability, and moreover it is often difficult to distinguish the edge of lower segment of the uterus and bladder. The station of the presenting fetal part deeper than or equal to +1 hinders its extraction, promotes damage to the lower part of the uterus, which often coexists with damage to the bladder. According to some authors it is an independent risk factor, which increases the risk of bladder damage two-fold [8]. Thus, there are to be expected clinical situations where there is a greater risk of damage to the uterus such as: PROM, the lower uterine segment in a premature birth, the malpresentation of the fetus, placenta praevia, placenta accrete, percreta and increta will increase the risk of injury of the bladder [24].

Fetal weight (more than $4000 \mathrm{~g}$ ) proved to be an independent factor increasing the risk of injury to the bladder by 2.85 times. This may be due to the need for larger incisions of the uterus [8].

Failed attempt of natural birth after cesarean section is also associated with a higher probability of bladder damage compared to elective surgery. But this should not be a reason to discourage patients from vaginal birth after cesarean delivery [25]. There are no studies comparing the effect of type of suturing the uterus during cesarean section and the risk of bladder injury in the next operation. However, there are studies, which suggest that the double-layer suturing of the uterus reduces the risk of intra-abdominal adhesions by seven times [26].

\section{HOW TO RECOGNIZE THE DAMAGE?}

The body of the bladder is the largest part lying between the apex, fundus and neck of the bladder. The trigone of the bladder is a triangle region on the posterior wall. Most bladder injuries during cesarean section occur at the dome of the bladder (48.0-76.2\%), with the remaining occurring at the body of the bladder (21.8-52.0\%) and the remaining cases concern the trigone of the bladder and ureters (3-8\%) [2, $7-9,27]$. According to the statistics, the first caesarean sections are dominated by damage to the top parts of the bladder (76.2\%) in the subsequent cesarean sections, the number of injuries to the body and the trigone of bladder $[7,8]$ is increased.

Identification and immediate repair of damage during surgery reduces the risk of further procedures as well as possible complications. Most of the injuries are recognized during surgery, during extraction of the fetus, suturing the uterus (about 62\%), during the inspection of the peritoneum (about 33\%) or when stuturing the fascia (about 12\%) [2, 26]. Visual inspection is the most reliable method of assessing the integrity of the bladder. The intraoperative symptoms which indicate bladder injury are the presence of urine outside the bladder, visualization of Foley catheter in the surgical field, gross hematuria in the Foley bag and visible wound or mucous membrane of the bladder [7, 25].

The bladder may be instilled with indigo carmine or methylene blue through a urethral catheter. The extravasation of this material from the bladder enables the surgeon to identify the injury and its location. If there is a concern whether there may have been ureteral involvement in the injury, then $40 \mathrm{mg}$ of Indigo carmine into the patient's IV may be introduced to examine for extravasation of dye proximal to the bladder, which would suggest ureteral injury. Assessment of the extent of damage to the trigone of the bladder and ureters is usually beyond the competence of obstetrician and requires consultation of the urologist $[25,27]$.

\section{HOW TO REPAIR DAMAGE?}

If there has been damage to the bladder, it is necessary to have it repaired during the same operation. Unrecognized damage and failure to implement treatment lead to the development of complications and requires re-operation $[2,7,8,27]$. Damage around the dome of the bladder less than $2 \mathrm{~mm}$ does not require repair or catheterization. In the event of damage up to $2 \mathrm{~cm}$, a single layer of sutures (usually 3-0 absorbable suture) should be put on the wound.

The damage extending more than $2 \mathrm{~cm}$ should be repaired with two layers of continuous sutures with delayed absorption. Firstly, the mucosa of the urinary bladder is sutured (3-0 absorbable suture); the second layer comprises submucosa and muscular layer (3-0 absorbable suture). Non-absorbable sutures should not be used because of 
the greater likelihood of urolithiasis, granulation scars and recurrent urinary tract infections [22, 27]. As mentioned above, damage in the area of a trigone of the urinary bladder can coexist with damage to the urethra and ureters; repair of this damage requires a lot of experience, thus, the help the urologist is needed $[27,28]$. In order to confirm bladder integrity it may be useful to fill the bladder with methylene blue dye.

Some centers routinely perform and recommend a cystoscopy after bladder repair surgery - especially involving posterior wall and the bladder trigone, which is often accompanied by rupture of the uterus towards the cervix [9]. The bladder should be continuously drained with the use of a Foley catheter for at least 7-10 days postoperatively. Sometimes it is appropriate to assume ureteral catheters and drainage of the peritoneal cavity. Most of the centers during the time of maintaining Foley catheter use the antibiotic prophylaxis according to urine culture from a sample taken directly from the Foley catheter $[2,7,8]$. However, there is no clear evidence of the need for such a procedure. However, it seems that the antibiotics use needs to be individually adjusted according to the clinical situation [12]. Damage to the urinary bladder heals well, if it is repaired immediately after damage. The most common postoperative complication is urinary tract infection and urinary incontinence $[7,8,27]$.

Damage to the bladder rarely remains undiagnosed during caesarean section. There are also many signs of the postoperative period, which suggest damage to the bladder. These symptoms may include hematuria, oliguria, abdominal pain, intestinal obstruction, ascites, peritonitis and septicemia. Cystography or computed tomography with cystography is used for the purpose of diagnosis of the initially unrecognized damage. In diagnostically obscure situations a method of exploratory laparotomy [27] should also be taken into account.

\section{SUMMARY}

As a result of the global increase in the number of deliveries by cesarean section and the increase in the number of patients who have had (at least one) cesarean section, who become pregnant again — the risk of damage to the bladder when performing the most common obstetric operation is real. The key role is a proper risk assessment before and during the operation and the immediate recognition of this complication. Implementation of appropriate procedures at the time of surgery and in the postoperative period can reduce the impact of the distant results of these most common urological complications of cesarean section.

\section{REFERENCES}

1. Mendez LE. latrogenic injuries in gynecologic cancer surgery. Surg Clin North Am. 2001; 81(4): 897-923, indexed in Pubmed: 11551133.

2. Phipps MG, Watabe B, Clemons JL, et al. Risk factors for bladder injury during cesarean delivery. Obstet Gynecol. 2005; 105(1): 156-60.

3. Rajasekar D, Hall M. Urinary tract injuries during obstetric intervention. Br J Obstet Gynaecol. 1997; 104(6): 731-734, indexed in Pubmed: 9197879.

4. Kaskarelis D, Sakkas J, Aravantinos D, et al. Urinary tract injuries in gynecological and obstetrical procedures. Int Surg. 1975; 60(1): 40-43, indexed in Pubmed: 1110127.

5. Lee JS, Choe JHo, Lee HS, et al. Urologic complications following obstetric and gynecologic surgery. Korean J Urol. 2012; 53(11): 795-799, doi: 10.4111/kju.2012.53.11.795, indexed in Pubmed: 23185673.

6. Eisenkop SM, Richman R, Platt LD, et al. Urinary tract injury during cesarean section. Obstet Gynecol. 1982; 60(5): 591-596, indexed in Pubmed: 7145252.

7. Rahman MS, Gasem T, Al Suleiman SA, et al. Bladder injuries during cesarean section in a University Hospital: a 25-year review. Arch Gynecol Obstet. 2009; 279(3): 349-352, doi: 10.1007/s00404-008-0733-1, indexed in Pubmed: 18648828.

8. Gungorduk K, Asicioglu O, Celikkol O, et al. latrogenic bladder injuries during caesarean delivery: a case control study. J Obstet Gynaecol. 2010; 30(7): 667-670, doi: 10.3109/01443615.2010.486086, indexed in Pubmed: 20925606.

9. Oliphant SS, Bochenska K, Tolge ME, et al. Maternal lower urinary tract injury at the time of Cesarean delivery. Int Urogynecol J. 2014; 25(12): 1709-1714, doi: 10.1007/s00192-014-2446-2, indexed in Pubmed: 24964762.

10. Kerr JM, Kerr JM. Technique of Lower Segment Caesarean Section, More Especially in "Suspect" and Infected Cases: (Section of Obstetrics and Gynaecology). Proc R Soc Med. 1936; 29(12): 1645-1647, indexed in Pubmed: 19990892.

11. Tarney CM. Bladder Injury During Cesarean Delivery. Curr Womens Health Rev. 2013; 9(2): 70-76, doi: 10.2174/157340480902140102151 729, indexed in Pubmed: 24876830.

12. Rodriguez $\mathrm{Al}$, Porter $\mathrm{KB}, \mathrm{O}$ 'Brien WF. Blunt versus sharp expansion of the uterine incision in low-segment transverse cesarean section. Am J Obstet Gynecol. 1994; 171 (4): 1022-1025, indexed in Pubmed: 7943065.

13. Wood RM, Simon $\mathrm{H}, \mathrm{Oz}$ AU. Pelosi-type vs. traditional cesarean delivery A prospective comparison. J Reprod Med. 1999; 44(9): 788-795, indexed in Pubmed: 10509303.

14. Malvasi A, Tinelli A, Gustapane S, et al. Surgical technique to avoid bladder flap formation during cesarean section. G Chir. 2011;32(11-12): 498-503, indexed in Pubmed: 22217381.

15. Tuuli MG, Odibo AO, Fogertey $P$, et al. Utility of the bladder flap at cesarean delivery: a randomized controlled trial. Obstet Gynecol. 2012; 119(4): 815-821, indexed in Pubmed: 22395144.

16. Cheung JPY, Tsang HHL, Cheung JJC, et al. Adjuvant therapy for the reduction of postoperative intra-abdominal adhesion formation. Asian J Surg. 2009; 32(3): 180-186, doi: 10.1016/S1015-9584(09)60392-4, indexed in Pubmed: 19656760.

17. Lyell DJ, Caughey $A B, H u E$, et al. Peritoneal closure at primary cesarean delivery and adhesions. Obstet Gynecol. 2005; 106(2): 275-280, doi: 10.1097/01.AOG.0000171120.81732.4c, indexed in Pubmed: 16055575.

18. Boland GM, Weigel RJ. Formation and prevention of postoperative abdominal adhesions. J Surg Res. 2006; 132(1): 3-12, doi: 10.1016/j. jss.2005.12.002, indexed in Pubmed: 16457846.

19. González-Quintero VH, Cruz-Pachano FE. Preventing adhesions in obstetric and gynecologic surgical procedures. Rev Obstet Gynecol. 2009. 2(1): 38-45, indexed in Pubmed: 19399293.

20. Nisenblat V, Barak S, Griness OB, et al. Maternal complications associated with multiple cesarean deliveries. Obstet Gynecol. 2006; 108(1): 21-26, indexed in Pubmed: 16816051.

21. Tulandi T, Agdi M, Zarei A, et al. Adhesion development and morbidity after repeat cesarean delivery. Am J Obstet Gynecol. 2009; 201(1): 56.e1-56.e6, doi: 10.1016/j.ajog.2009.04.039, indexed in Pubmed: 19576375.

22. Hema KR, Johanson R. Techniques for performing caesarean section. Best Pract Res Clin Obstet Gynaecol. 2001; 15(1): 17-47, doi: 10.1053/ /beog.2000.0147, indexed in Pubmed: 11359313. 
23. Alexander JM, Leveno KJ, Rouse DJ, et al. Comparison of maternal and infant outcomes from primary cesarean delivery during the second compared with first stage of labor. Obstet Gynecol. 2007; 109(4): 917-921, indexed in Pubmed: 17400854.

24. Hammad FT, AIQaiwani KM, Shirodkar SS. The role of urologists in the management of urological injuries during obstetric and gynaecologic surgery. Int Urogynecol J. 2010; 21(10): 1237-1241, doi: 10.1007/s00192010-1173-6, indexed in Pubmed: 20458464.

25. Cahill AG, Stout MJ, Stamilio DM, et al. Risk factors for bladder injury in patients with a prior hysterotomy. Obstet Gynecol. 2008; 112(1): 116-120, indexed in Pubmed: 18591316.
26. Blumenfeld YJ, Caughey AB, El-Sayed YY, et al. Single- versus double-layer hysterotomy closure at primary caesarean delivery and bladder adhesions. BJOG. 2010; 117(6): 690-694, doi: 10.1111/j.1471-0528.2010.02529.x, indexed in Pubmed: 20236104.

27. Sharp HT, Adelman MR. Prevention, Recognition, and Management of Urologic Injuries During Gynecologic Surgery. Obstet Gynecol. 2016; 127(6): 1085-1096, indexed in Pubmed: 27159741.

28. Davis JD. Management of injuries to the urinary and gastrointestinal tract during cesarean section. Obstet Gynecol Clin North Am. 1999; 26(3): 469-480, indexed in Pubmed: 10472066. 